\title{
Immunohistochemical and functional correlations of renal cyclooxygenase- 2 in experimental diabetes
}

\author{
Radko Komers, ${ }^{1}$ Jessie N. Lindsley, ${ }^{1}$ Terry T. Oyama, ${ }^{1}$ William E. Schutzer, ${ }^{2}$ John F. Reed, ${ }^{2}$ \\ Scott L. Mader, ${ }^{2}$ and Sharon Anderson ${ }^{1,2}$ \\ ${ }^{1}$ Division of Nephrology and Hypertension, Department of Medicine, Oregon Health Sciences University, Portland, Oregon, USA \\ ${ }^{2}$ Research Service, Portland Veterans Affairs Medical Center, Portland, Oregon, USA
}

Address correspondence to: Sharon Anderson, Division of Nephrology and Hypertension, Oregon Health Sciences University, PP262, 3314 SW US Veterans Hospital Road, Portland, Oregon 97201-2940, USA.

Phone: (503) 494-8490; Fax: (503) 721-7810; E-mail: anderssh@ohsu.edu.

Received for publication May 2, 2000, and accepted in revised form February 12, 2001.

\begin{abstract}
Prostaglandins (PGs) generated by the enzyme cyclooxygenase (COX) have been implicated in the pathological renal hemodynamics and structural alterations in diabetes mellitus, but the role of individual COX isoenzymes in diabetic nephropathy remains unknown. We explored COX-1 and COX-2 expression and hemodynamic responses to the COX-1 inhibitor valeryl salicylate (VS) or the COX-2 inhibitor NS398 in moderately hyperglycemic, streptozotocin-diabetic (D) and control (C) rats. Immunoreactive COX-2 was increased in D rats compared with $\mathrm{C}$ rats and normalized by improved glycemic control. Acute systemic administration of NS398 induced no significant changes in mean arterial pressure and renal plasma flow in either $\mathrm{C}$ or $\mathrm{D}$ rats but reduced glomerular filtration rate in $\mathrm{D}$ rats, resulting in a decrease in filtration fraction. VS had no effect on renal hemodynamics in $\mathrm{D}$ rats. Both inhibitors decreased urinary excretion of $\mathrm{PGE}_{2}$. However, only NS398 reduced excretion of thromboxane $A_{2}$. In conclusion, we documented an increase in renal cortical COX-2 protein expression associated with a different renal hemodynamic response to selective systemic COX-2 inhibition in D as compared with $\mathrm{C}$ animals, indicating a role of COX-2-derived PG in pathological renal hemodynamic changes in diabetes.
\end{abstract}

J. Clin. Invest. 107:889-898 (2001).

\section{Introduction}

The role of cyclooxygenase (COX) metabolites of arachidonic acid in the pathogenesis of diabetic nephropathy has been suggested in a number of clinical and experimental studies. In 1985, Schambelan et al. (1) demonstrated an increase in conversion of exogenous arachidonate to prostaglandin $\mathrm{E}_{2}\left(\mathrm{PGE}_{2}\right)$, prostaglandin $\mathrm{F}_{2 \alpha}$, prostaglandin $\mathrm{D}_{2}$, and thromboxane $\mathrm{B}_{2}\left(\mathrm{TxB}_{2}\right)$ in glomeruli from diabetic rats. In the early stages of nephropathy, vasodilatory prostaglandins, such as $\mathrm{PGE}_{2}$ and prostacyclin, have been implicated in mediating alterations in renal hemodynamics in humans with type 1 diabetes (2-5), as well as in experimental models of diabetes (6-10). Furthermore, inhibition of actions of the vasoconstrictor prostanoid thromboxane $\mathrm{A}_{2}\left(\mathrm{Tx}_{2}\right)$ has been associated with amelioration of renal hemodynamic and structural changes and albuminuria in experimental and clinical diabetes (11-14).

Two isoforms of COX have been identified, COX-1 and COX-2. COX-1 is constitutively expressed in most tissues. In the normal adult kidney, COX-1 has been localized to arteries and arterioles, glomeruli and collecting ducts (15). In contrast, COX-2 operates as an inducible enzyme with low or undetectable levels in most tissues, and its expression can be markedly increased by a number of inflammatory, mitogenic, and physical stimuli (16-18). Although considered to be an inducible enzyme, COX-2 is constitutively expressed in occasional renal cells of the thick ascending loop of Henle (TALH) and in the region of the macula densa (MD) of the rat kidney, and in podocytes in the human kidney (18-21). Both COX isoforms metabolize arachidonic acid to generate prostaglandins (PGs) and thromboxanes. Recent evidence has suggested that COX-2-derived PGs play a role in physiological regulation in the normal kidney, being involved in modulation of afferent arteriolar vasoconstriction after stimulation of tubuloglomerular feedback (TGF) (22), attenuation of myogenic afferent responses to increases in renal perfusion pressure (RPP) (23), and stimulation of renin release (24-26).

Renal hemodynamic changes early in the course of clinical and experimental diabetes are characterized by elevations in glomerular filtration rate (GFR). On the single-nephron level, the major renal hemodynamic alteration in diabetes has been identified as disproportionally decreased afferent arteriolar resistance (27-29), resulting in elevated glomerular capillary pressure $\left(\mathrm{P}_{\mathrm{GC}}\right)$ $(27,28)$. Although the underlying causes for these abnormalities remain elusive, decreased activity of TGF (30-32) and impaired myogenic responses to changes in RPP (33) have been suggested as possible mechanisms contributing to the pathogenesis of renal hemodynamic changes in diabetes. Furthermore, the role of 
the renin-angiotensin system (RAS) in the pathogenesis of nephropathy has been well established, although not completely understood (34).

Although the contribution of eicosanoids to the pathogenesis of hemodynamic and structural changes in the diabetic kidney seems to be well established, the role of individual COX isoenzymes in this process remains unknown. With respect to its physiological actions, we hypothesized that COX-2 could be an isoform involved in increased production of eicosanoids in diabetes and thus play a role in diabetes-induced renal hemodynamic alterations. To address this issue we explored renal cortical tissue COX-2 expression and renal and systemic hemodynamic responses to the selective COX-2 inhibitor, NS398, in control and diabetic rats. To further elucidate the role of COX isoforms in the development of diabetic nephropathy, effects of selective inhibition and renal expression of COX-1 also have been determined in an additional group of diabetic rats.

\section{Methods}

The diabetic rat model. Studies were conducted in adult male Sprague-Dawley rats with initial weights of approximately $300 \mathrm{~g}$. The rats were made diabetic by intraperitoneal injection of streptozotocin (Sigma Chemical Co., St. Louis, Missouri, USA), $65 \mathrm{mg} / \mathrm{kg}$ body weight. Three days later, induction of diabetes was confirmed by measurements of tail blood glucose (BG) level using a reflectance meter (One Touch II; Lifescan, Milpetas, California, USA). Diabetic rats received daily evening injections of ultralente insulin (Iletin II; Eli Lilly and Co., Indianapolis, Indiana, USA) in doses individually adjusted to maintain BG levels between 200 and $300 \mathrm{mg} / \mathrm{dl}$ (11-17 mmol/l). A subgroup of diabetic rats received intensive insulin treatment ( $4 \mathrm{U}$ of ultralente insulin, twice daily) to achieve near-normal metabolic control. BG levels were monitored at least weekly in all diabetic rats. All studies were performed after 4 to 5 weeks' duration of diabetes. Age-matched (protein expression and prostanoid-excretion studies) and weight-matched (hemodynamic studies) nondiabetic Sprague-Dawley rats served as controls. All rats were fed standard rat chow (Rodent Laboratory Chow 5001; Ralston Purina, Richmond, Indiana, USA) ad libitum. These studies were approved by the Portland Veteran Affairs Institutional Animal Care and Use Subcommittee.

Immunoblotting and immunohistochemistry. Groups of control rats, moderately hyperglycemic diabetic rats, and diabetic rats on intensive insulin treatment were anesthetized with intraperitoneal injection of methohexitone (Brevital; $50 \mathrm{mg} / \mathrm{kg}$ ). The abdominal aorta was exposed by a midabdominal incision and cannulated $5 \mathrm{~mm}$ above the bifurcation with a PE-50 catheter. After collection of blood samples for determination of glucose level and glycosylated hemoglobin (HbA1c), the right kidney was removed, decapsulated, divided into cortical and medullary portions, and snap-frozen in liquid nitrogen for Western blot analysis. The left kidney was then perfused with ice-cold PBS $(30 \mathrm{ml})$, excised, and immersed in 10\% formalin. The fixed kidneys were dehydrated through a graded series of ethanols, embedded in paraffin, sectioned at $4 \mu \mathrm{m}$ thickness, and placed onto glass slides.

Immunoblotting. Kidney cortices were finely minced and then disrupted in a glass-glass motor-driven Kontes tissue homogenizer in $10 \mathrm{mM}$ Tris, $1 \mathrm{mM}$ EDTA, $20 \mu \mathrm{g} / \mathrm{ml}$ leupeptin, $20 \mu \mathrm{g} / \mathrm{ml}$ benzamidine, and $40 \mu \mathrm{g} / \mathrm{ml}$ PMSF. Homogenates were centrifuged at $500 \mathrm{~g}$ for 15 minutes at $4^{\circ} \mathrm{C}$, and the resulting nucleifree supernatant was centrifuged at 100,000 $\mathrm{g}$ for 60 minutes at $4^{\circ} \mathrm{C}$. The total protein content of each resulting pellet (microsome) was equalized by dilution in SDS-PAGE sample buffer and incubated for $5 \mathrm{~min}$ utes at $97^{\circ} \mathrm{C}$. Denatured proteins $(20 \mu \mathrm{g})$ were then separated through an SDS-polyacrylamide (8\%) gel and transferred to PVDF membranes (Bio-Rad Laboratories Inc., Hercules, California, USA). Membranes were extensively washed with Tris-buffered saline (TBS-T; $10 \mathrm{mM}$ Tris, $150 \mathrm{mM} \mathrm{NaCl}, 0.05 \%$ Tween-20) and then blocked overnight with TBS-T containing $5 \%$ nonfat dry milk. After blocking, membranes were again extensively washed with TBS-T and incubated overnight with a rabbit polyclonal anti-murine COX-2 or COX-1 antisera (Cayman Chemical, Ann Arbor, Michigan, USA) diluted 1:800 in TBS-T. Immunodetection was accomplished by incubating membranes with a goat anti-rabbit IgG secondary Ab conjugated with horseradish peroxidase (HRP) for 45 minutes (1:100,000; Pierce Chemical Co., Rockford, Illinois, USA) in TBS-T containing $5 \%$ nonfat dry milk. Visualization was performed with an enhanced chemiluminescence (ECL) Western blotting kit (Supersignal West Dura; Pierce Chemical Co.) according to the manufacturer's instructions. Resultant films (Eastman Kodak Co. Scientific Imaging Systems, New Haven, Connecticut, USA) were scanned using a flatbed scanner and images analyzed with NIH Image software with the gel-plotting macro. The membranes were then stripped in stripping buffer (Chemicon International, Temecula, California, USA) for 15 minutes at room temperature, blocked for 30 minutes in a blocking buffer provided by the manufacturer, and reincubated for 1 hour at room temperature with goat anti-actin $\mathrm{Ab}$ (Santa Cruz Biotechnology Inc., Santa Cruz, California, USA), followed by 45 -minute incubation with anti-goat IgG secondary Ab conjugated with HRP (1:4000; Amersham Pharmacia Biotech, Piscataway, New Jersey, USA), and the reaction was visualized with ECL as described above.

Immunobistochemistry. The same antisera as described above (Cayman Chemical) were used for immunohistochemical detection of renal COX-2 and COX-1. Sections were deparaffinized in xylene, rehydrated through graded ethanols to water, and pretreated by steaming in 10\% CITRA buffer (BioGenex Laboratories, San Ramon, California, USA). After being treated with protein-blocking solution, the slides were incubated overnight at $4^{\circ} \mathrm{C}$ with primary $\mathrm{Ab}$ (diluted 1:200) or with the same concentration of nonimmune rabbit $\operatorname{IgG}$ 
as a control. Endogenous peroxidase activity was blocked with $3 \% \mathrm{H}_{2} \mathrm{O}_{2}$ solution in methanol. The primary $\mathrm{Ab}$ was localized using the Vectastain ABC-Elite peroxidase detection system (Vector Laboratories, Burlingame, California, USA). This was followed by reaction with diaminobenzidine as chromogen and counterstaining with hematoxylin (Sigma Chemical Co.). Sections of each diabetic kidney were processed in parallel with appropriate control tissue.

Design of hemodynamic studies. To explore the acute systemic and renal hemodynamic effects of COX-2 inhibition, control and diabetic rats were studied before and after administration of the specific COX-2 inhibitor NS398 (Cayman Chemical). In addition, effects of valeryl salicylate (VS) (Cayman Chemical), a selective COX-1 inhibitor (35), were also evaluated in a separate group of diabetic rats. BG level was measured preceding and just before the completion of the experiments. After the surgical preparation described below and after 90 minutes of equilibration, all rats underwent baseline measurements of mean arterial pressure (MAP), GFR, renal plasma flow (RPF), renal vascular resistance (RVR), urinary flow (UF), and urinary sodium $\left(\mathrm{U}_{\mathrm{Na}} \mathrm{V}\right)$. Thereafter, rats received a continuous 10 -minute infusion of NS398 $(0.3 \mathrm{mg} / \mathrm{kg})$ or VS (6 mg/ $\mathrm{kg}$ body weight) in $10 \%$ ethanol in $0.9 \% \mathrm{NaCl}$ heated to $37^{\circ} \mathrm{C}$ or the same volume of vehicle $(10 \%$ ethanol in $0.9 \% \mathrm{NaCl}, 100 \mu \mathrm{l}$; vehicle 1), and all measurements were repeated to assess changes from baseline. When these measurements were completed, effects of a higher dose of NS398 or VS (1.5 $\mathrm{mg} / \mathrm{kg}$ and $30 \mathrm{mg} / \mathrm{kg}$ body weight) were assessed in a similar manner including the effects of vehicle alone (vehicle 2). Since there has been scarce information on the hemodynamic effects of systemic NS398 administration, the choice of the lower dose was based on studies showing that dose as the $\mathrm{ED}_{50}$ for the anti-inflammatory effect of the inhibitor in the rat (36). According to the same report, both doses of NS398 used in the present studies were at least 20 times below the range in which the loss of specificity for COX- 2 could be expected. To our knowledge, VS has not yet been tested in in vivo hemodynamic studies. Considering the higher $\mathrm{ED}_{50}$ of VS for COX-1 than of NS398 for COX-2, we chose an approach similar to that of Traynor et al. (26), using, on the molar basis, an approximately 10 times higher dose of VS than NS398. MAP was continuously monitored throughout the study. The values obtained at mid-time points of each clearance period were used for statistical analysis.

Surgical preparation and functional studies. Rats were anesthetized with Inactin $(100 \mathrm{mg} / \mathrm{kg}$ intraperitoneally) and placed on a temperature-regulated table. The left femoral artery was catheterized, and a baseline blood collection was obtained for measurements of hematocrit (Hct) and inulin and para-aminohippurate (PAH) "blanks". This arterial catheter was used for subsequent periodic blood sampling and measurement of MAP using an electronic transducer connected to a direct-writing recorder. After tracheostomy, jugular venous catheters were inserted for infusions of inulin, $\mathrm{PAH}$, and plasma. Intravenous infusions of rat plasma and $10 \%$ inulin solution in $0.9 \% \mathrm{NaCl}$ were started at rates of 6.0 and $1.2 \mathrm{ml} / \mathrm{h}$, respectively. $\mathrm{PAH}$ was added to the inulin solution at a concentration of $0.8 \%$. The left ureter was catheterized for urine collection. Euvolemia was maintained by infusing isooncotic rat serum at $6 \mathrm{ml} / \mathrm{h}$ in a total amount equal to $1 \%$ of the body weight, followed by a reduction in infusion rate to $1.6 \mathrm{ml} / \mathrm{kg} / \mathrm{h}$ to maintain Hct constant. Diabetic rats received extra saline to match the excessive urinary losses during the procedure. Timed samples of urine $(\sim 15$ minutes) were collected for determination of flow rate and inulin and PAH concentrations. Arterial blood samples were taken at the mid-time point of each period for determinations of Hct and plasma concentrations of inulin and PAH. These measurements permitted calculation of GFR (inulin clearance), RPF (PAH clearance), filtration fraction (FF), and RVR by standard formulas. After experiments, aortic blood was taken in a chilled syringe and then subdivided into tubes containing EDTA (plasma renin concentration; PRC), or heparin coating (HBA1c). The left kidney was rapidly excised and weighed.

Urinary excretion of COX metabolites. Control and moderately hyperglycemic diabetic rats underwent baseline timed (6-8 hour) urine collections for measurements of urinary excretion of $\mathrm{PGE}_{2}$ and $\mathrm{TxB}_{2}$. Two days after baseline collections, diabetic rats were randomized to receive single subcutaneous injections of NS398 (1.5 mg/kg in $100 \mu \mathrm{l}$ DMSO, $n=5)$, VS (30 $\mathrm{mg} / \mathrm{kg}$ in $100 \mu \mathrm{l} \mathrm{DMSO}, n=5)$, or DMSO vehicle alone $(n=5)$. Control nondiabetic rats $(n=4)$ were injected with DMSO, and the urine collections were then repeated. The urine was collected in volumetric tubes immersed in a mixture of ice and dry ice. After completion of collections, the urine was immediately stored at $-70^{\circ} \mathrm{C}$ and kept until further analysis.

Analytical methods. Inulin concentrations in plasma and urine were measured using a macroanthrone method, and PAH levels were measured spectrophotometrically. HBA1c was determined by affinity column chromatography (Glyco-Gel B; Pierce Chemical Co.). Plasma renin concentrations were measured by diluting rat plasma with maleate buffer, $\mathrm{pH} 6.0$, and adding $100 \mu \mathrm{l}$ of rat anephric plasma mixed with $20 \mu \mathrm{l} / \mathrm{ml}$ dimercaprol and 8-hydroxyquinoline for a total of $600 \mu$ l. The sample was separated into two parts for $4^{\circ} \mathrm{C}$ and $37^{\circ} \mathrm{C}$ incubation for 1 hour and assayed according to the angiotensin I RIA Kit protocol (NEN Life Science Products Inc., Boston, Massachusetts, USA). Urinary $\mathrm{PGE}_{2}$ and its metabolites were analyzed using enzyme immunoassay (EIA; Cayman Chemical) after conversion to bicyclo$\mathrm{PGE}_{2}$ according to the manufacturer's instructions. Urinary concentrations of $\mathrm{TxB}_{2}$, a stable metabolite of TxA were analyzed by EIA (Amersham Pharmacia Biotech).

Statistical analysis. Data are expressed as mean \pm SEM. All analyses were performed by ANOVA followed by a Scheffé test. Differences in responses to treatments 
Table 1

General characteristics of control and diabetic rats

\begin{tabular}{|c|c|c|c|c|c|c|c|}
\hline Group & $n$ & $\begin{array}{l}\text { BWT } \\
\text { (g) }\end{array}$ & $\begin{array}{l}\text { LKW } \\
(\mathrm{g})\end{array}$ & $\begin{array}{c}\text { LKW/BWT } \\
(100 \mathrm{~g} \text { BWT })\end{array}$ & $\begin{array}{c}\text { BG } \\
(\mathrm{mg} / \mathrm{dl})\end{array}$ & $\begin{array}{l}\text { HBA1c } \\
(\%)\end{array}$ & Hct \\
\hline \multicolumn{8}{|c|}{ Protein expression studies } \\
\hline $\mathrm{C}$ & 5 & $392 \pm 7$ & $1.41 \pm 0.03$ & $0.36 \pm 0.01$ & $93 \pm 8$ & $3.0 \pm 0.1$ & \\
\hline D & 5 & $312 \pm 22^{C}$ & $2.18 \pm 0.31^{\mathrm{A}, \mathrm{B}}$ & $0.71 \pm 0.11^{\mathrm{A}, \mathrm{B}}$ & $401 \pm 39^{A, B}$ & $9.8 \pm 0.3^{\mathrm{A}, \mathrm{B}}$ & \\
\hline D-IIT & 4 & $331 \pm 20^{C}$ & $1.38 \pm 0.04$ & $0.42 \pm 0.01$ & $127 \pm 9 \mathrm{C}$ & $4.1 \pm 0.1 \mathrm{C}$ & \\
\hline \multicolumn{8}{|c|}{ Hemodynamic studies } \\
\hline C-VE & 9 & $341 \pm 7$ & $1.30 \pm 0.10$ & $0.38 \pm 0.02$ & $92 \pm 4$ & $3.7 \pm 0.3$ & $0.42 \pm 0.0$ \\
\hline C-NS398 & 6 & $343 \pm 5$ & $1.25 \pm 0.04$ & $0.37 \pm 0.01$ & $95 \pm 7$ & $4.8 \pm 0.1$ & $0.41 \pm 0.0$ \\
\hline D-VE & 8 & $350 \pm 13$ & $1.83 \pm 0.14^{\mathrm{A}}$ & $0.52 \pm 0.03^{\mathrm{A}}$ & $320 \pm 17^{A}$ & $9.2 \pm 0.9^{\mathrm{A}}$ & $0.43 \pm 0.0$ \\
\hline D-NS398 & 10 & $350 \pm 8$ & $1.90 \pm 0.11^{\mathrm{A}}$ & $0.54 \pm 0.03^{\mathrm{A}}$ & $314 \pm 15^{A}$ & $8.8 \pm 0.6^{A}$ & $0.42 \pm 0.0$ \\
\hline D-VS & 7 & $362 \pm 4$ & $1.79 \pm 0.14^{\mathrm{A}}$ & $0.49 \pm 0.04^{\mathrm{A}}$ & $264 \pm 24^{A}$ & $9.2 \pm 0.4^{\mathrm{A}}$ & $0.42 \pm 0.0$ \\
\hline
\end{tabular}

C, control; D, diabetes; VE, vehicle; IIT, intensive insulin treatment; VS, valeryl salicylate; BWT, body weight; LKW, left kidney weight; BG, blood glucose; HBA1c, glycosylated hemoglobin; Hct, hematocrit. ${ }^{A} P<0.001$ vs. control; ${ }^{\mathrm{B}} P<0.01$ vs. D-IIT; ${ }^{\mathrm{C}} P<0.05$ vs. $C$.

between control and diabetic rats were tested by twoway repeated-measures ANOVA, using Statview SE and Graphics software (Brainpower, Calabasas, California, USA). A $P$ value of less than 0.05 was viewed as statistically significant.

\section{Results}

Renal cortical COX expression studies. Diabetic rats demonstrated lower weight gain, renal hypertrophy assessed by the left kidney weight and kidney/body weight ratio, and increased BG and HBA1c levels as compared with controls (Table $1, P<0.01$ ). In diabetic rats on intensive insulin treatment, kidney hypertrophy, BG, and HBA1c were markedly reduced $(P<0.01$ vs. moderately hyperglycemic rats), although the BG and HBA1c values remained higher than in control animals $(P<0.05)$. Western blot analysis revealed increased expression of COX-2 immunoreactive protein in the renal cortex of diabetic rats as compared with control animals or diabetic rats on intensive insulin treatment $(P<0.05$, Figure 1). In control rats, immunohistochemical staining localized COX-2 immunoreactivity in sporadic individual MD cells and cells of TALH (Figure 2). In contrast, diabetic kidneys demonstrated immunostaining of multiple cells in MD regions and clusters of COX2 -positive non-MD cells of TALH (Figure 2). Furthermore, COX-2 immunoreactivity was detectable in occasional podocytes both in control and diabetic rats. In intensively treated diabetic rats, cortical immunohis- tochemical expression of COX-2 resembled findings in controls (Figure 2). In contrast to COX-2, control and diabetic rats and diabetic rats on intensive insulin treatment demonstrated no differences in COX-1 cortical protein expression (Figure 1). Immunohistochemical studies showed expression of COX-1 protein in collecting ducts. There were no differences in distribution or intensity of immunostaining of renal COX-1 in the three groups of rats (data not shown).

Hemodynamic studies. General characteristics of rats undergoing hemodynamic studies are shown in Table 1. Body weights and hematocrits were similar in all groups of rats. Diabetic rats had renal hypertrophy, moderate hyperglycemia, and an increase in HBA1c $(P<0.001)$. Effects of COX inhibitors on blood pressure and renal hemodynamics are shown in Table 2 and Figure 3. No significant changes in MAP were observed with vehicle or with NS398 (Table 2). Diabetic rats demonstrated baseline increases in GFR $(P<0.001$ vs. control) and FF $(P<0.05$ vs. control) (Figure 3), whereas baseline RPF and RVR were similar in all groups. No significant changes in GFR in response to COX-2 inhibition were observed in control rats. In contrast, the higher dose of NS398 reduced GFR in diabetic rats $(P<0.01$ vs. basal and NS398 $0.3 \mathrm{mg} / \mathrm{kg}$ ). In diabetic rats, the post-treatment GFR was not different from controls. Since the RPF was not influenced by the NS398 treatment, FF decreased markedly in diabetic rats $(P<0.05$ vs. basal and NS398 $0.3 \mathrm{mg} / \mathrm{kg}$ ). In diabetic rats receiving the COX-1

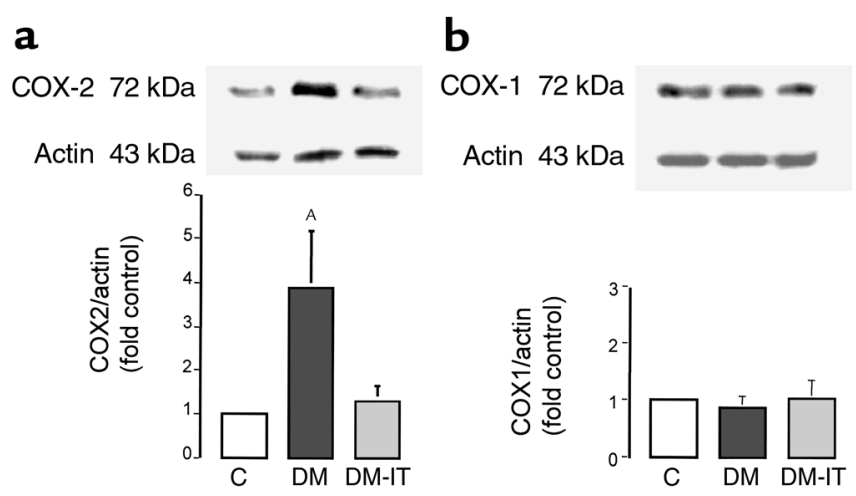

\section{Figure 1}

Expression of COX-2 and COX-1 immunoreactive proteins, shown as COX/actin ratio, in renal cortex of control $(C ; n=5)$, moderately hyperglycemic diabetic rats $(\mathrm{DM} ; n=5)$, and diabetic rats on intensive insulin treatment (DM-IT; $n=4)$. Moderately hyperglycemic diabetic rats demonstrated an increase in cortical COX-2 expression as compared with control rats. This was reversed by improved metabolic control in diabetic rats on intensive insulin treatment. No differences in COX-1 expression were found between control and diabetic rats. ${ }^{A} P<0.05$.

(1)



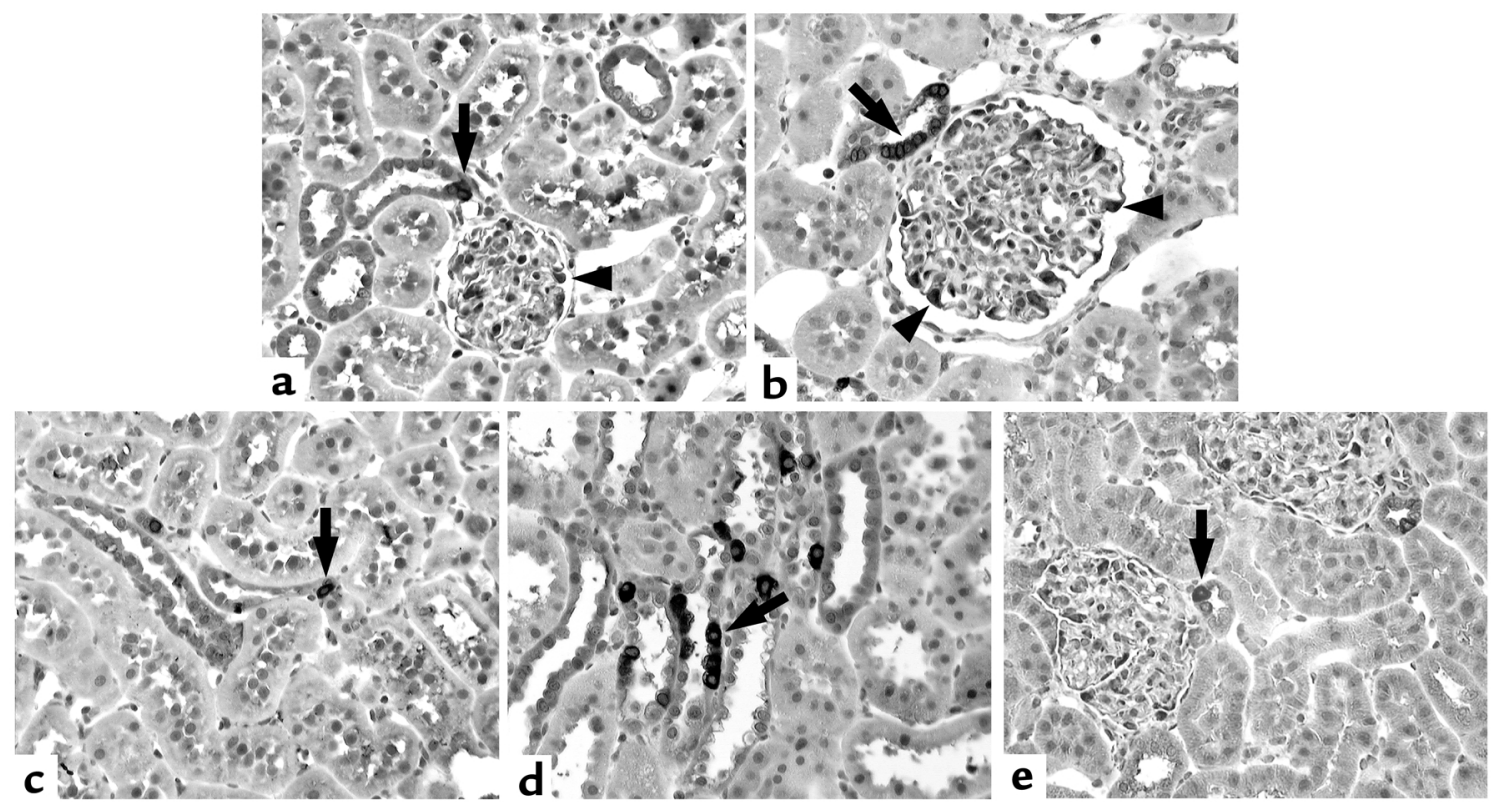

\section{Figure 2}

Localization of immunoreactive COX-2 in MD ( $\mathbf{a}$ and $\mathbf{b}$, arrows) and in non-MD tubular cells ( $\mathbf{c}$ and $\mathbf{d}$, arrows) of control ( $\mathbf{a}$ and $\mathbf{c}$ ) and diabetic rats (b and $\mathbf{d}$ ). In control rats, COX-2 immunoreactivity was present in occasional cells. In contrast, diabetic kidneys demonstrated immunostaining of groups of cells both in MD regions and non-MD cells of TALH. COX-2 was also detected in occasional podocytes (arrowheads) both in control (a) and diabetic glomeruli (b). Findings in diabetic rats on intensive insulin treatment resembled those in control rats $(\mathbf{e})$. $\times 400$.

inhibitor VS, the low dose $(6 \mathrm{mg} / \mathrm{kg})$ was the highest tolerated by all rats. In some rats (30\%), administration of a higher dose $(30 \mathrm{mg} / \mathrm{kg})$ caused severe hypotension, followed by respiratory arrest and death within 5 minutes after the start of infusion. An autopsy of those animals revealed no gastrointestinal or other bleeding. On the contrary, enhanced blood clotting was observed at the tip of the venous catheter during the infusion of the higher dose of VS. Therefore, we can not exclude pulmonary embolization as a cause of death in those animals. In rats that remained hemodynamically stable during the infusion of the higher dose of VS, the MAP and renal hemodynamics did not significantly change from baseline.

The data for UF and $\mathrm{U}_{\mathrm{Na}} \mathrm{V}$ are summarized in Table 2. Diabetic rats exhibited polyuria throughout the experimentation as compared with controls $(P<0.01)$. The UF remained stable in vehicle-treated control, as well as in vehicle-treated diabetic animals and in diabetic animals treated with COX-1 inhibitor. In contrast, a gradual decrease in UF was noted in NS398-treated diabetic rats, with a significant difference after the higher dose of the inhibitor $(P<0.05 \mathrm{vs}$. baseline and NS398 $0.3 \mathrm{mg} / \mathrm{kg}$ ). The trend in UF was different between the vehicle-treated and NS398-treated diabetic animals as assessed by two-way repeated-measures ANOVA $(P<0.05 ; F=3.33)$. There were no baseline differences in $\mathrm{U}_{\mathrm{Na}} \mathrm{V}$ between

\section{Table 2}

the control and diabetic rats. In the control rats, NS398 induced a gradual decrease in this parameter with a significantly lower value after the higher dose of the inhibitor as compared with baseline $(P<0.05)$ and corresponding period of the vehicle-treated control rats $(P<0.05)$. Although not significantly reduced as compared with baseline, the $\mathrm{U}_{\mathrm{Na}} \mathrm{V}$ after the lower dose of NS398 was already different from vehicletreated control animals $(P<0.05)$. A similar, although not statistically significant, trend in $\mathrm{U}_{\mathrm{Na}} \mathrm{V}$ was observed in NS398-treated diabetic rats. After the

Effects of NS398 on renal excretory functions and plasma renin concentration in control and diabetic rats

\begin{tabular}{|c|c|c|c|c|c|}
\hline & & $\begin{array}{c}\text { MAP } \\
(\mathrm{mmHg})\end{array}$ & $\begin{array}{c}\text { UF } \\
(\mu \mathrm{l} / \mathrm{min})\end{array}$ & $\begin{array}{c}U_{\mathrm{Na}} V \\
(\mu \mathrm{mol} / \mathrm{min})\end{array}$ & $\begin{array}{c}\text { PRC } \\
(\text { ng Ang l/ml/h) }\end{array}$ \\
\hline C-VE & $\begin{array}{l}\text { Basal } \\
\text { Vehicle } 1 \\
\text { Vehicle } 2\end{array}$ & $\begin{array}{l}113 \pm 3 \\
115 \pm 3 \\
113 \pm 2\end{array}$ & $\begin{array}{l}7.6 \pm 0.8 \\
7.0 \pm 1.0 \\
6.8 \pm 1.0\end{array}$ & $\begin{array}{l}0.51 \pm 0.37 \\
0.50 \pm 0.10 \\
0.56 \pm 0.20\end{array}$ & $58 \pm 15$ \\
\hline C-NS398 & $\begin{array}{c}\text { Basal } \\
\text { NS398 } 0.3 \\
\text { NS398 } 1.5\end{array}$ & $\begin{array}{c}118 \pm 5 \\
119 \pm 5 \\
115 \pm 10\end{array}$ & $\begin{array}{l}5.1 \pm 0.5 \\
4.5 \pm 0.3 \\
4.5 \pm 0.4\end{array}$ & $\begin{array}{c}0.29 \pm 0.17 \\
0.16 \pm 0.07 \\
0.11 \pm 0.07^{\mathrm{A}, \mathrm{B}}\end{array}$ & $72 \pm 25$ \\
\hline D-VE & $\begin{array}{l}\text { Basal } \\
\text { Vehicle } 1 \\
\text { Vehicle } 2\end{array}$ & $\begin{array}{l}109 \pm 5 \\
111 \pm 5 \\
113 \pm 8\end{array}$ & $\begin{array}{l}17.2 \pm 4.5^{c} \\
18.8 \pm 5.0^{C} \\
20.1 \pm 7.4^{C}\end{array}$ & $\begin{array}{l}0.52 \pm 0.14 \\
0.69 \pm 0.15 \\
0.91 \pm 0.22\end{array}$ & $45 \pm 13$ \\
\hline D-NS398 & $\begin{array}{c}\text { Basal } \\
\text { NS398 } 0.3 \\
\text { NS398 } 1.5\end{array}$ & $\begin{array}{l}116 \pm 5 \\
123 \pm 4 \\
114 \pm 6\end{array}$ & $\begin{array}{c}25.8 \pm 6.0^{C} \\
22.2 \pm 6.6^{C} \\
18.8 \pm 7.3^{A, C}\end{array}$ & $\begin{array}{c}0.31 \pm 0.06 \\
0.45 \pm 0.18 \\
0.28 \pm 0.13^{B}\end{array}$ & $28 \pm 6^{\mathrm{D}}$ \\
\hline D-VS & $\begin{array}{c}\text { Basal } \\
\text { VS } 6.0 \\
\text { VS } 30.0\end{array}$ & $\begin{array}{l}120 \pm 2 \\
122 \pm 3 \\
125 \pm 4\end{array}$ & $\begin{array}{c}23.1 \pm 6.0^{C} \\
28.9 \pm 6.6^{C} \\
30.2 \pm 10.9^{C}\end{array}$ & $\begin{array}{l}0.67 \pm 0.26 \\
0.91 \pm 0.33 \\
0.68 \pm 0.23\end{array}$ & $37 \pm 9$ \\
\hline
\end{tabular}

Values are mean \pm SE. Group abbreviations are as in Table $1 .{ }^{A} P<0.05$ vs. basal; ${ }^{B} P<0.05$ vs. vehicle-treated animals; $C P<0.01$ vs. control animals; ${ }^{D} P<0.05$ vs. C-NS398. 

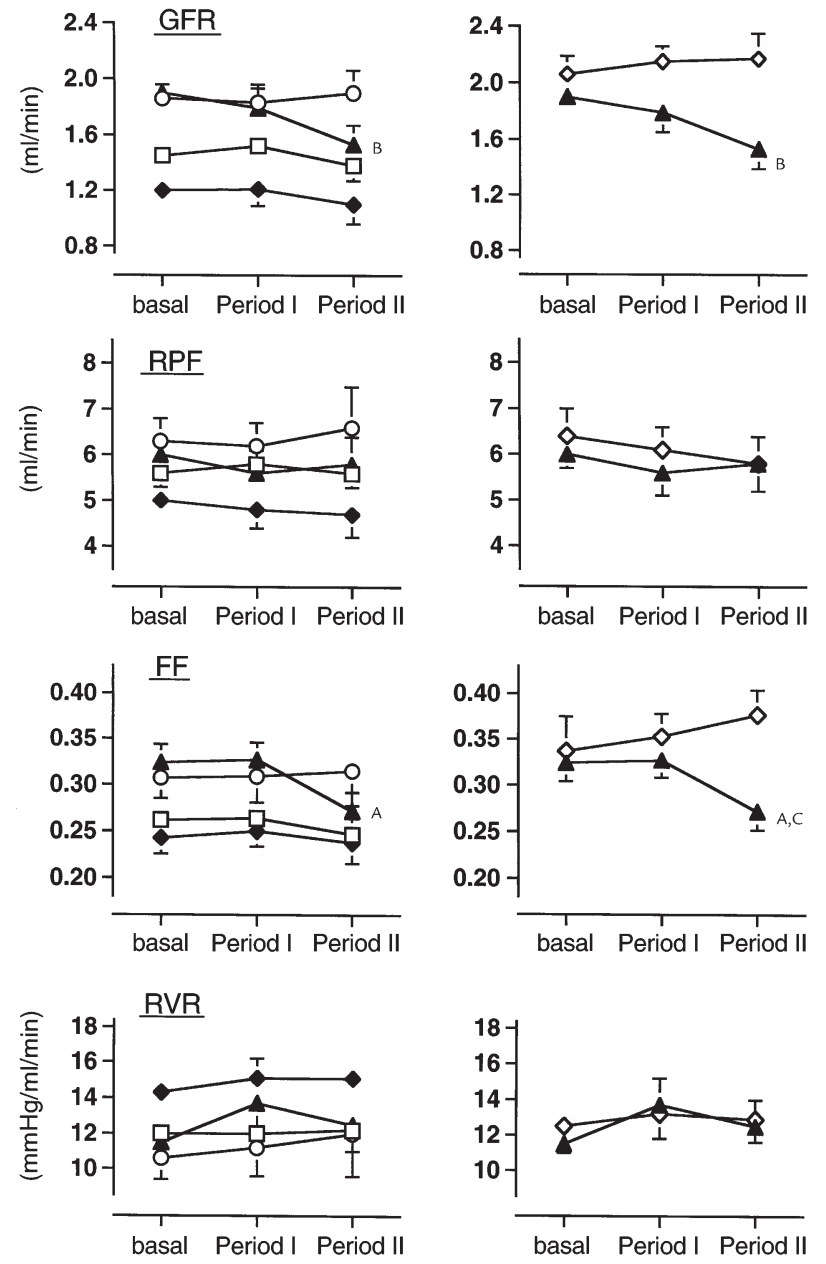

Figure 3

Effects of acute selective COX-2 inhibition with NS398 (Period I, 0.3 $\mathrm{mg} / \mathrm{kg}$; Period II, $1.5 \mathrm{mg} / \mathrm{kg}$ ) or vehicle on GFR, RPF, FF, and RVR in control and diabetic rats. As shown in the left panels, NS398 induced no changes in renal hemodynamics in control rats. By contrast, diabetic rats responded to COX-2 inhibition with significant decreases in GFR and FF. Right panels depict disparate renal hemodynamic responses induced by COX- 2 and COX- 1 inhibitors in diabetic rats. Unlike NS398, administration of VS (Period I, 6 mg/kg; Period II, 30 $\mathrm{mg} / \mathrm{kg}$ ) did not influence GFR. Open squares, control vehicle-treated rats; filled diamonds, control rats treated with NS398; open circles, diabetic vehicle-treated rats; filled triangles, diabetic rats treated with NS398; open diamonds, diabetic rats treated with VS. ${ }^{A} P<0.05$ vs. basal; ${ }^{B} P<0.001$ vs. basal; ${ }^{C} P<0.05$ vs. diabetic rats treated with VS.

higher dose of the inhibitor, these rats demonstrated lower $\mathrm{U}_{\mathrm{Na}} \mathrm{V}$ as compared with their vehicle-treated counterparts $(P<0.05)$. There were no significant changes in diuresis and natriuresis associated with administration of VS. Plasma renin concentrations, determined after the completion of renal hemodynamic studies, are shown in Table 2. No differences in PRC were found when control or diabetic animals, treated with NS398 or VS, were compared with vehicle-treated counterparts. However, there was a significant difference in PRC between the diabetic and control rats treated with NS398 $(P<0.05)$.
Urinary excretion of $P G E_{2}$ and $T x B_{2}$. Diabetic rats demonstrated moderate hyperglycemia (baseline: 266 \pm 12 ; post-treatment: $271 \pm 15 \mathrm{mg} / \mathrm{dl}$ ). There were no significant differences in mean $B G$ values between the groups of diabetic rats determined before measurements of baseline $\mathrm{PGE}_{2}$ and $\mathrm{TxB}_{2}$ excretion (data not shown). Effects of COX-2 and COX-1 inhibitors on urinary excretion of $\mathrm{PGE}_{2}$ and $\mathrm{TxB}_{2}$ are summarized in Figure 4. At baseline, all groups of diabetic rats had increased excretion of $\mathrm{PGE}_{2}$ as compared with nondiabetic animals. Excretion of $\mathrm{TxB}_{2}$ in individual diabetic groups was not significantly increased. However, when pooled together, $\mathrm{TxB}_{2}$ excretion in diabetic rats was significantly higher than in controls $(P<0.05)$. Both NS398 and VS induced marked, similar decreases in urinary excretion of $\mathrm{PGE}_{2}(P<0.05)$. In contrast, $\mathrm{TxB}_{2}$ excretion was reduced only in diabetic rats treated with COX-2 inhibitor $(P<0.05)$. Unlike the intravenous administration of VS used in hemodynamic studies, subcutaneous administration of the agent was well tolerated in all animals. No changes in urinary excretion of $\mathrm{PGE}_{2}$ or $\mathrm{TxB}_{2}$ were observed in control and diabetic rats treated with vehicle.

\section{Discussion}

In the present study we report an increase in COX-2 protein expression in the renal cortex of moderately hyperglycemic diabetic rats as compared with nondiabetic control animals. Furthermore, this increase in COX-2 expression in diabetic rats was normalized by improved metabolic control, indicating the causal role of the diabetic state in the genesis of this abnormality. In accordance with previous findings by other investigators $(18$, 21), COX-2 immunostaining in the kidneys of control rats was detectable only in occasional cells of MD, TALH, and glomeruli. In diabetic rats, renal COX-2 immunoreactivity was observed in the same regions as in control animals; however, intense COX-2 immunostaining was found in clusters and groups of cells, particularly in MD regions. Corresponding to previous observations (37), we found no differences in cortical expression of COX-1 between control and diabetic rats.

Having observed increased COX-2 protein expression in cortices of diabetic rats, we embarked on further studies exploring whether the tissue changes also have a pathophysiological impact in modulating renal hemodynamics in diabetes. Acute systemic inhibition of COX-2 with the specific inhibitor NS398 had no impact on renal hemodynamics and blood pressure in control rats. In contrast, NS398 caused a modest decrease in GFR in diabetic animals. The RPF remained stable in diabetic animals, resulting in a decrease in FF. As in the control rats, no significant changes in MAP were observed in response to the COX-2 inhibitor. Masferrer and coworkers (36) showed remarkable selectivity of NS398 for COX-2 in doses as high as $30 \mathrm{mg} / \mathrm{kg}$ in the rat. Therefore, the contribution of COX-1 inhibition to our observed effects of NS398, should be negligible. However, those studies (36) were conducted in an exper- 
imental model of inflammation, and COX-1 involvement was assessed by the incidence of development of lesions in gastric mucosa. The selectivity of NS398 has not been sufficiently tested in hemodynamic and renal studies. To further elucidate the role of individual COX isoforms in the pathogenesis of diabetic hyperfiltration and to discriminate the possible contribution of COX-1 inhibition to the effects of NS398, we determined systemic and renal hemodynamic responses to the selective COX-1 inhibitor VS in an additional group of diabetic rats. This intervention did not influence renal and systemic hemodynamics. In this context, the COX-2 inhibitor NS 398 seems to possess an ability to selectively target the renal microcirculatory imbalance characteristic for early stages of diabetic nephropathy (27, 38 ). The decrease in GFR observed in diabetic rats corresponds to some, but not all (39), previous clinical (2-4) and experimental (7-10) studies with nonspecific COX inhibitors. Our data suggest that the major part of these effects has been induced via COX-2 inhibition.

We assumed that COX-2-derived vasodilatory PG influenced predominantly afferent arteriolar tone in diabetic animals. Having performed whole-kidney hemodynamic studies, we can only indirectly address renal microcirculatory changes induced by COX-2 inhibition. However, the changes observed after NS398 infusion suggest that the renal microcirculatory effects of COX-2 inhibition in diabetes are more complex. The decrease in GFR was accompanied by stable values in RPF and RVR. Therefore, a decrease in postglomerular vascular tone must have been involved in the effects of NS398. Since COX-2 is also involved in generation of $\mathrm{TxA}_{2}$, a potent constrictor of glomerular arterioles and mesangial cells (40), it is conceivable that the hemodynamic effects of NS398 were also mediated by decreased generation of this metabolite. This interpretation is supported by the analysis of urinary excretion of $\mathrm{PGE}_{2}$ and $\mathrm{TxB}_{2}$ before and after selective inhibition of COX isoforms. Diabetic rats excreted increased amounts of $\mathrm{PGE}_{2}$. A significant difference in baseline $\mathrm{TxB}_{2}$ excretion between diabetic and control rats was observed only after pooling the data of all diabetic rats studied in this protocol. The absence of a large increase in $\mathrm{TxB}_{2}$ excretion at this early time point is in accord with earlier studies by Craven and DeRubertis $(11,41)$. Although increased $\mathrm{Tx}_{2}$ urinary excretion is present in rats with severe diabetes and no insulin treatment early in the course of diabetes, significantly elevated urinary $\mathrm{TxB}_{2}$ excretion in moderately hyperglycemic rats may not be detectable until 3 months after induction of diabetes. Both COX-1 and COX-2 inhibitors induced marked decreases in urinary excretion of $\mathrm{PGE}_{2}$. However, only COX-2 inhibition was associated with a significant reduction of urinary $\mathrm{TxB}_{2}$. Using severely hyperglycemic rats, Uriu et al. (12) reported a decrease in $\mathrm{FF}$ and a preservation of renal blood flow in diabetic rats treated with a selective $\mathrm{TxA}_{2}$ inhibitor. In the present study, renal hemodynamic responses to NS398 in diabetic rats resembled those observed after $\mathrm{TxA}_{2}$ inhibition. The use of the moderately hyperglycemic model of diabetes lacking the early increase in urinary $\mathrm{TxB}_{2}$ does not preclude a contribution of $\mathrm{Tx} \mathrm{A}_{2}$ inhibition to the renal effects of NS398 at this stage of experimental diabetes. Of note, neither COX-1 nor COX-2 inhibition caused reductions in RPF. A decrease in RPF has been observed previously by some investigators in diabetic rats treated with nonselective COX inhibitors (7). Considering approximately $50 \%$ suppression of urinary $\mathrm{PGE}_{2}$ excretion in response to isoform-selective inhibitors in the present studies, as compared with $70-90 \%$ achieved by nonselective inhibitors $(39,42,43)$, this finding is not surprising. It appears that concomitant inhibition of both isoforms is necessary to elicit significant renal vasoconstriction in diabetic rats.

Several pathways have been identified linking the diabetic milieu with enhanced prostanoid production. Activation of protein kinase C (PKC) by hyperglycemia has been shown to activate phospholipase $\mathrm{A}_{2}$ and stim-

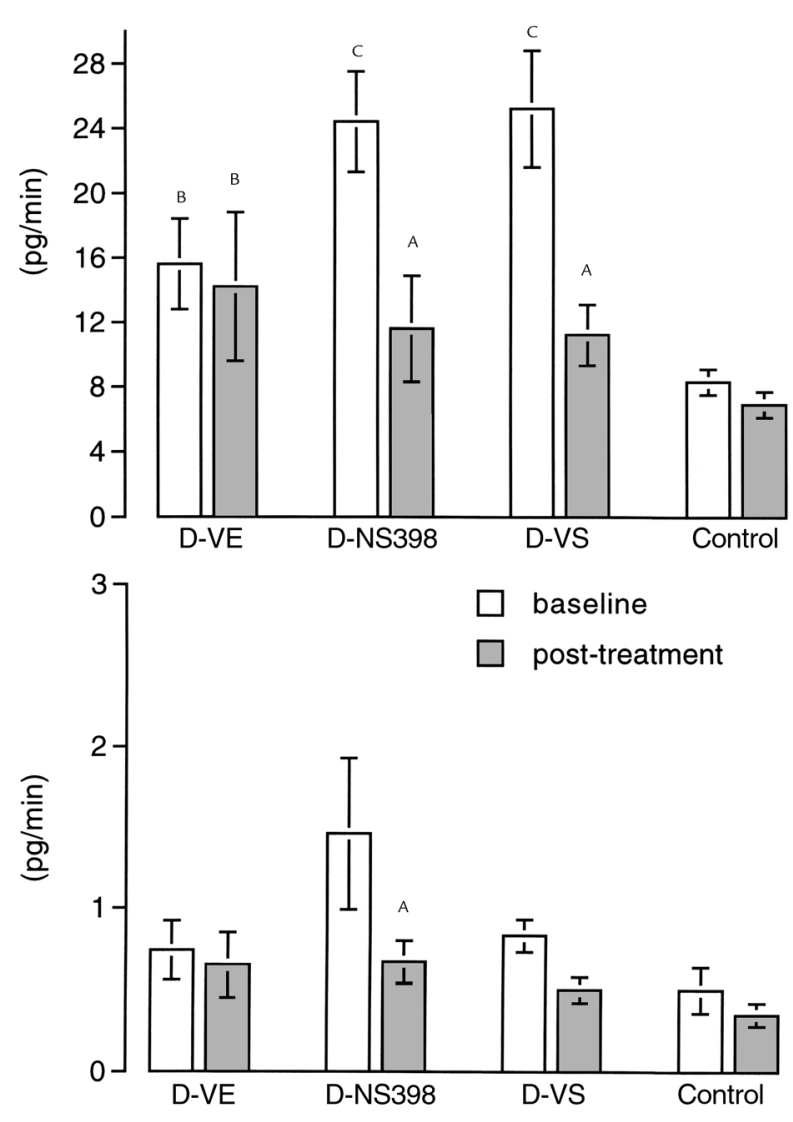

Figure 4

Effects of COX-2 inhibitor NS398 $(1.5 \mathrm{mg} / \mathrm{kg})$ and COX-1 inhibitor VS (VS, $30 \mathrm{mg} / \mathrm{kg}$ ) on urinary excretion of $\mathrm{PGE}_{2}$ and $\mathrm{TxB}_{2}$ in diabetic rats. Diabetic rats demonstrated increased baseline excretion of $\mathrm{PGE}_{2}(P<0.01)$ and $\mathrm{TxB}_{2}(P<0.05)$ as compared with control rats. Both inhibitors induced significant decreases in urinary $\mathrm{PGE}_{2}$ excretion $(P<0.05)$. However, only treatment with NS398 was associated with a reduction of $\mathrm{TxB}_{2}(P<0.05)$. D-VE, diabetic rats treated with vehicle; D-NS398, diabetic rats treated with NS398; D-VS, diabetic rats treated with VS; Control, control rats administered vehicle. ${ }^{A} P<0.05$ vs. baseline; ${ }^{B} P<0.05$ vs. control; ${ }^{C} P<0.01$ vs. control. 
ulate arachidonic acid release and $\mathrm{PGE}_{2}$ production in mesangial cells $(44,45)$. COX-2, as an inducible enzyme, is likely to be involved in this pathway. Moreover, phorbol esters, PKC activators, have been shown to activate COX-2 $(46,47)$. Several novel pathways linking the diabetic state with increased COX-2 expression have been communicated just recently. Cheng et al. (48) demonstrated that activation of COX-2 in MD cells induced by low extracellular $\mathrm{NaCl}$ requires activation of p38 mitogen-activated protein kinase. In parallel, there is emerging evidence suggesting that p38 kinase is activated and overexpressed in the diabetic kidney $(49,50)$. Another line of evidence suggests that COX-2 may be, in diabetes, activated by glycosylation products (51). Interestingly, COX-2 expression and cortical localization in diabetic rats strongly resembled findings by Wang et al. (21) in the rat remnant kidney model. Therefore, it is likely that these two conditions, characterized by glomerular hyperfiltration, share some mechanisms resulting in activation of COX-2. For example, both conditions have been associated with activation of renal renin-angiotensin system (52-54) and can be ameliorated by treatment with converting enzyme inhibitors (ACEI) or AT1 receptor blockers (55-58). Angiotensin II (Ang II) can influence COX-2 expression and/or activity. However, these effects are still controversial. Ang II increases PG production in the kidney, which in turn is thought to buffer vasoconstriction responses to Ang II (43). $\mathrm{TxA}_{2}$ production in the kidney is also increased by Ang II $(43,59)$. Furthermore, studies conducted in normal rat nephrons (60) in glomeruli from rats with bilateral ureteral obstruction (61) or in cultured mesangial cells of obese Zucker rats (59) demonstrated a decrease in COX activity in response to treatment with ACEI. This interpretation, however, has been challenged recently by two studies showing an increase in MD COX-2 expression in response to ACEI /AT1 inhibition $(47,62)$, suggesting that on a long-term basis, Ang II decreases COX-2 expression in the MD.

Based on in vitro studies by Akai et al. (63), Wang and coworkers (21) suggested mechanical stress as a possible cause of COX-2 overexpression in the rat remnant kidney model. However, in our model we did not observe clear differences in glomerular COX-2 expression between control and diabetic rats. Stretchinduced gene and protein expression have been documented also in tubular cells (64). It is not clear whether changes in distal tubular volumes and flows in diabetes are sufficient to stretch this part of the nephron. However, early distal tubular flows in moderately hyperglycemic diabetic rats are not different from nondiabetic animals $(32,65)$. Therefore, mechanical stressinduced activation of COX-2 in MD cells in diabetes seems to be unlikely.

Changes in distal tubular solute delivery may be another factor underlying COX-2 abnormalities in the diabetic kidney. Low-salt diet increases expression of COX-2 in MD in the normal rat, which in turn stimu- lates renin secretion $(18,24,26)$. In moderately hyperglycemic diabetic rats, distal $\mathrm{NaCl}$ delivery is decreased (32) and could be theoretically sensed by MD cells as a false stimulus for COX-2 expression. Ichihara et al. (22) have suggested a functional synergistic link between COX-2 and neuronal nitric oxide synthase (NOS1). This enzyme is highly expressed in MD cells and NOS1derived NO plays a major role in modulating TGF (66). COX-2 is stimulated as a result of NOS1 activation, and NOS-1-derived NO production induced by activation of TGF is attenuated by concomitant COX-2 inhibition (22). We have reported recently enhanced renal NOS1 activity in diabetic kidneys $(67,68)$. This is another possible pathway leading to activation of COX-2 in diabetes. On the other hand, it is also possible that decreased NO generation from the MD contributed to the effects of COX-2 inhibitor.

We observed no effect of acute COX-2 inhibition on PRC in control rats. This finding is not surprising, since COX-2 inhibition has been shown to suppress renin release in rats fed a low-salt diet $(18,24,26)$. However, diabetic rats treated with NS398 demonstrated lower PRC as compared with NS398-treated control animals, though the difference in PRC was not significant as compared with vehicle-treated control or diabetic animals. We cannot formulate any conclusions based on this finding, but this phenomenon may suggest an enhanced responsiveness of renin release to COX-2 inhibition in experimental diabetes. These pathways are currently being explored in our laboratory using a different experimental design. In control rats, COX-2 inhibition caused a decrease in natriuresis, and a similar trend was observed in diabetic rats, combined with a significant decrease in diuresis. These observations are in accordance with well-established effects of PG on renal sodium and water handling and correspond to recent clinical reports focusing on COX-2 inhibitors (69). We did not quantify COX-2 protein expression in medulla, but we did not find any apparent differences in medullary immunohistochemical expression of the enzyme between the control and diabetic rats. Possible longterm consequences of antinatriuretic effects of COX-2 inhibition, such as the increase in blood pressure, are unknown and must be tested in long-term studies.

In conclusion, using a combined experimental approach, we documented an increase in renal cortical COX-2 protein expression associated with differential renal hemodynamic responses to selective systemic COX-2 inhibition in diabetic rats as compared with control animals. This indicates a role for COX-2-derived PG in the pathogenesis of renal hemodynamic changes in diabetes. In contrast to COX-2, COX-1 expression was similar in control and diabetic rats, and administration of the selective COX-1 inhibitor did not influence renal hemodynamics in diabetic rats. The renal hemodynamic pattern observed in NS398-treated diabetic rats suggests a possible nephroprotective potential of COX-2 inhibition in this condition. This view is supported by two recent studies by Sanchez et al. (70) and, in partic- 
ular, by Wang et al. (71) in the remnant kidney model, showing the slower development of proteinuria and attenuation of renal structural damage in animals treated with selective COX-2 inhibitors. Whether this treatment represents a new therapeutic option for patients at risk of developing diabetic nephropathy or a useful addition to currently prescribed therapeutic agents remains to be established in further studies.

\section{Acknowledgments}

These studies were supported, in part, by grants from the American Diabetes Association and the NIH (AG14699) (to S. Anderson), and by the Research Service, Department of Veteran Affairs and Medical Research Foundation of Oregon (to S.L. Mader). We are grateful to Aaron Janowsky, Portland Veterans Affairs Research Service, for sharing imaging equipment with our group.

1. Schambelan, M., et al. 1985. Increased prostaglandin production by glomeruli isolated from rats with streptozotocin-induced diabetes mellitus. J. Clin. Invest. 75:404-412.

2. Esmatjes, E., et al. 1985. Renal hemodynamic abnormalities in patients with short term insulin-dependent diabetes mellitus. J. Clin. Endocrinol. Metab. 60:1231-1236.

3. Hommel, E., et al. 1987. Effects of indomethacin on kidney function in type 1 (insulin-dependent) diabetic patients with nephropathy. Diabetologia. 30:78-81.

4. Gambardella, S., et al. 1988. Renal hemodynamics and urinary excretion of 6-keto-prostaglandin F1 alpha and thromboxane B2 in newly diagnosed type 1 diabetic patients. Diabetes. 37:1044-1048.

5. Viberti, G.C., Benigni, A., Bognetti, E., Remuzzi, G., and Wiseman, M.J. 1989. Glomerular hyperfiltration and urinary prostaglandins in type 1 diabetes mellitus. Diabet. Med. 6:219-223.

6. Kasiske, B.L., O’Donnell, M.P., and Keane, W.F. 1985. Glucose-induced increases in renal hemodynamic function. Possible modulation by renal prostaglandins. Diabetes. 34:360-364.

7. Jensen, P.K., Steven, K., Blaehr, H., Christiansen, J.S., and Parving, H.-H. 1986. Effects of indomethacin on glomerular hemodynamics in experimental diabetes. Kidney Int. 29:490-495.

8. Moel, D.I., Safirstein, R.L., McEnvoy, R.C., and Hsueh, W. 1987. Effect of aspirin on experimental diabetic nephropathy. J. Lab. Clin. Med. 110:300-307.

9. Craven, P.A., Caines, M.A., and DeRubertis, F.R. 1987. Sequential alterations in glomerular prostaglandin and thromboxane synthesis in diabetic rats: relationship to the hyperfiltration of early diabetes. Metabolism. 36:95-103.

10. Perico, N., et al. 1992. Atrial natriuretic peptide and prostacyclin synergistically mediate hyperfiltration and hyperperfusion of diabetic rats. Diabetes. 41:533-538.

11. Craven, P.A., Melhem, M.F., and De Rubertis, F.R. 1992. Thromboxane in the pathogenesis of glomerular injury in diabetes. Kidney Int. 42:937-946.

12. Uriu, K., Kaizu, K., Hashimoto, O., Komine, N., and Etoh, S. 1994. Acute and chronic effects of thromboxane A2 inhibition on the renal hemodynamics in streptozotocin-induced diabetic rats. Kidney Int. 45:794-802.

13. Esmatjes, E., et al. 1990. Effects of thromboxane synthesis inhibitor triflusal on renal hemodynamics in microalbuminuric diabetic patients. Diabetes Care. 13:1114-1117.

14. Kontessis, P.S., et al. 1993. Effect of thromboxane synthase inhibitor on renal function in diabetic nephropathy. J. Lab. Clin. Med. 121:415-423.

15. Smith, W.L., and Bell, T.G. 1978. Immunohistochemical localization of the prostaglandin-forming cyclooxygenase in renal cortex. Am. J. Physiol. 235:F451-F457.

16. Tetsuka, T., et al. 1996. Nitric oxide amplifies interleukin 1-induced cyclooxygenase- 2 expression in rat mesangial cells. J. Clin. Invest. 97:2051-2056.

17. Fletcher, B.S., Kujubu, D.A., Perrin, D.M., and Herschman, H.R. 1992. Structure of the mitogen-inducible TIS 10 gene and demonstration that the TIS 10 -encoded protein is a functional prostaglandin $\mathrm{G} / \mathrm{H}$ synthase. J. Biol. Chem. 267:4338-4344.

18. Harris, R.C., et al. 1994. Cyclooxygenase-2 is associated with the macula densa of rat kidney and increases with salt restriction. J. Clin. Invest. 94:2504-2510.

19. Vio, C.P., Cespedes, C., Gallardo, P., and Masferrer, J.L. 1997. Renal iden- tification of cyclooxygenase-2 in a subset of thick ascending limb cells. Hypertension. 30:687-692.

20. Kömhoff, M., Gröne, H., Klein, T., Seyberth, H.W., and Nüsing, R.M. 1997. Localization of cyclooxygenase- 1 and -2 in adult and fetal human kidney: implication for renal function. Am. J. Physiol. 272:F460-F468.

21. Wang, J.-L., Cheng, H.-F., Zhang, M.-Z., McKanna, J.A., and Harris, R.C. 1998. Selective increase of cyclooxygenase-2 expression in a model of renal ablation. Am. J. Physiol. 275:F613-F622.

22. Ichihara, A., Imig, J.D., Inscho, E.W., and Navar, L.G. 1998. Cyclooxygenase-2 participates in tubular flow-dependent afferent arteriolar tone: interaction with neuronal NOS. Am. J. Physiol. 275:F605-F612.

23. Ichihara, A., Imig, J.D., and Navar, L.G. 1999. Cyclooxygenase-2 modulates afferent arteriolar responses to increases in pressure. Hypertension. 34:843-847.

24. Harding, P., et al. 1997. Cyclooxygenase-2 mediates increased renal renin content by low-sodium diet. Hypertension. 29:297-302.

25. Wang, J.-L., Cheng, H.-F., and Harris, R.C. 1999. Cyclooxygenase-2 inhibition decreases renin content and lowers blood pressure in a model of renovascular hypertension. Hypertension. 34:96-101.

26. Traynor, T.R., Smart, A., Briggs, J.P., and Schnermann, J. 1999. Inhibition of macula densa-stimulated renin secretion by pharmacological blockade of cyclooxygenase-2. Am. J. Physiol. 277:F706-F710.

27. Hostetter, T.H., Troy, J.L., and Brenner, B.M. 1981. Glomerular hemodynamics in experimental diabetes mellitus. Kidney Int. 19:410-415.

28. Zatz, R., et al. 1986. Prevention of diabetic glomerulopathy by pharmacological amelioration of glomerular capillary hypertension. J. Clin. Invest. 77:1925-1930.

29. Ohishi, K., and Carmines, P.K. 1995. Superoxide dismutase restores the influence of nitric oxide on renal arterioles in diabetes mellitus. J. Am. Soc. Nephrol. 5:1559-1566.

30. Blantz, R.C., Peterson, O.W., Gushwa, L., and Tucker, B.J. 1982. Effect of modest hyperglycemia on tubuloglomerular feedback activity. Kidney Int. 22(Suppl. 12):S206-S212.

31. Woods, L.L., Mizelle, H.L., and Hall, J.E. 1987. Control of renal hemodynamics in hyperglycemia: possible role of tubuloglomerular feedback. Am. J. Physiol. 252:F65-F73.

32. Vallon, V., Blantz, R.C., and Thomson, S. 1995. Homeostatic efficiency of tubuloglomerular feedback is reduced in established diabetes mellitus in rats. Am. J. Physiol. 269:F876-F883.

33. Hayashi, K., Epstein, M., Loutzenhiser, R., and Forster, H. 1992. Impaired myogenic responsiveness of the efferent arteriole in streptozotocininduced diabetic rats: role of eicosanoid derangements. J. Am. Soc. Nephrol. 2:1578-1586.

34. Anderson, S. 1998. Physiologic actions and molecular expression of the renin-angiotensin system in the diabetic rat. Miner. Electrolyte Metab. 24:406-411.

35. Bhattacharyya, D.K., Lecomte, M., Dunn, J., Morgans, D.J., and Smith, W.L. 1995. Selective inhibition of prostaglandin endoperoxide synthase1 (cyclooxygenase-1) by valerylsalicylic acid. Arch. Biochem. Biophys. 317:19-24.

36. Masferrer, J.L., et al. 1994. Selective inhibition of inducible cyclooxygenase 2 in vivo is antiinflammatory and nonulcerogenic. Proc. Natl. Acad. Sci. USA. 91:3228-3232.

37. Fang, C., Jiang, Z., and Tomlinson, D.R. 1997. Expression of constitutive cyclo-oxygenase (COX-1) in rats with streptozotocin-induced diabetes: effects of treatment with evening primrose oil or an aldose reductase inhibitor on COX-1 mRNA levels. Prostaglandins Leukot. Essent. Fatty Acids. 56:157-163.

38. Ohishi, K., Carmines, P.K., Inscho, E.W., and Navar, L.G. 1992. EDRFangiotensin II interactions in rat juxtamedullary afferent and efferent arterioles. Am. J. Physiol. 263:F900-F906.

39. Bank, N., Lahorra, M.A., Aynedjian, H.S., and Schlondorff, D. 1988. Vasoregulatory hormones and the hyperfiltration of diabetes. Am. J. Physiol. 254:F202-F209.

40. Remuzzi, G., Fitzgerald, G.A., and Patrono, C. 1992. Thromboxane synthesis and action within the kidney. Kidney Int. 41:1483-1493.

41. DeRubertis, F.R., and Craven, P.A. 1993. Eicosanoids in the pathogenesis of the functional and structural alterations of the kidney in diabetes. Am. J. Kidney Dis. 22:727-735.

42. Pinilla, J.M., Alberola, A., Gonzalez, J.D., Quesada, T., and Salazar, F.J. 1993. Role of prostaglandins on the renal effects of angiotensin and interstitial pressure during volume expansion. Am. J. Physiol. 265:R1469-R1474.

43. Navar, L.G., et al. 1996. Paracrine regulation of the renal microcirculation. Physiol. Rev. 76:425-536.

44. Williams, B., and Schrier, R.W. 1993. Glucose-induced protein kinase C activity regulates arachidonic acid release and eicosanoid production by cultured glomerular mesangial cells. J. Clin. Invest. 92:2889-2896.

45. Koya, D., et al. 1997. Characterization of protein kinase C beta isoform activation on the gene expression of transforming growth factor-beta, extracellular matrix components, and prostanoids in the glomeruli of diabetic rats. J. Clin. Invest. 100:115-126. 
46. Guan, Y., et al. 1997. Cloning, expression, and regulation of rabbit cyclooxygenase-2 in renal medullary interstitial cells. Am. J. Physiol. 273:F18-F26.

47. Cheng, H.-F., et al. 1999. Angiotensin II attenuates renal cortical cyclooxygenase-2 expression. J. Clin. Invest. 103:953-961.

48. Cheng, H.-F., Wang, J.-L., Zhang, M.-Z., McKanna, J.A., and Harris, R.C 2000 . Role of $\mathrm{p} 38$ in the regulation of renal cortical cyclooxygenase-2 expression by extracellular chloride. J. Clin. Invest. 106:681-688.

49. Kang, S.-W., Adler, S.G., LaPage, J., and Natarajan, R. 2000. Glomerular p38 mitogen-activated protein kinase activity (MAPK) and MAPK kinase (MKK) 3/6 mRNA expression and activity are increased in early diabetic nephropathy. J. Am. Soc. Nephrol. 11:644A. (Abstr.)

50. Yehualaeshet, T., et al. 2000. Activation of p38 MAPK in the diabetic kidney via MKK3 dependent pathway. J. Am. Soc. Nephrol. 11:656A. (Abstr.)

51. Amore, A., Cirina, P., Conti, G., Peruzzi, L., and Coppo, R. 2000. Possible role of glycated albumin filtered during diabetic glomerulopathy, in the activation of tubular cells and progression of diabetic nephropathy. $J$. Am. Soc. Nephrol. 11:634A. (Abstr.)

52. Pelayo, J.C., Quan, A.H., and Shanley, P.F. 1990. Angiotensin II control of the renal microcirculation in rats with reduced renal mass. Am. J. Physiol. 258:F414-F422.

53. Correa-Rotter, R., Hostetter, T.H., Manivel, J.C., and Rosenberg, M.E. 1992. Renin expression in renal ablation. Hypertension. 20:483-490.

54. Anderson, S., Jung, F.F., and Ingelfinger, J.R. 1993. Renal reninangiotensin system in diabetes: functional, immunohistochemical, and molecular biological correlations. Am. J. Physiol. 265:F477-F486.

55. Anderson, S., Rennke, H., and Brenner, B. 1992. Nifedipine versus fosinopril in uninephrectomized diabetic rats. Kidney Int. 41:891-897.

56. Anderson, S., Rennke, H.G., and Brenner, B.M. 1986. Therapeutic advantage of converting enzyme inhibitors in arresting progressive renal disease associated with systemic hypertension in the rat. J. Clin. Invest. 77:1993-2000.

57. Wu, L.L., et al. 1997. Transforming growth factor $\beta 1$ and renal injury following subtotal nephrectomy in the rat: role of the renin-angiotensin system. Kidney Int. 51:1553-1567.

58. Lafayette, R.A., Mayer, G., Park, S.K., and Meyer, T.W. 1992. Angiotensin II receptor blockade limits glomerular injury in rats with reduced renal mass. J. Clin. Invest. 90:766-772.

59. Higueruelo, S., Vaquero, M., Pastor, C., Galimany, R., and Romero, R.
1998. Fosinopril ameliorates exogenous cholesterol-induced incipient glomerular lesions in obese Zucker rats. Effects on eicosanoid secretion. Nephrol. Dial. Transplant. 13:2227-2233.

60. Don, B.R., Blake, S., Hutchison, F.N., Kaysen, G.A., and Schambelan, M. 1989. Dietary protein intake modulates glomerular eicosanoid production in the rat. Am. J. Physiol. 256:F711-F718.

61. Yanagisawa, H., Morrissey, J., and Klahr, S. 1991. Mechanism of enhanced eicosanoid production by isolated glomeruli from rats with bilateral ureteral obstruction. Am. J. Physiol. 261:F248-F255.

62. Wolf, K., et al. 1999. Inhibition of the renin-angiotensin system upregulates cyclooxygenase- 2 expression in the macula densa. Hypertension. 34:503-507.

63. Akai, Y., Homma, K., Burns, K., and Harris, R.C. 1994. Mechanical stretch/relaxation of cultured rat mesangial cells induces protooncogenes and cyclooxygenase. Am. J. Physiol. 267:C482-C490.

64. Ricardo, S.D., Franzoni, D.F., Roesener, C.D., Crisman, J.M., and Diamond, J.R. 2000. Angiotensinogen and AT(1) antisense inhibition of osteopontin translation in rat proximal tubular cells. Am. J. Physiol. 278:F708-F716.

65. Pollock, C.A., Lawrence, J.R., and Field, M.J. 1991. Tubular sodium handling and tubuloglomerular feedback in experimental diabetes mellitus. Am. J. Physiol. 260:F946-F952.

66. Wilcox, C.S., et al. 1992. Nitric oxide synthase in macula densa regulates glomerular capillary pressure. Proc. Natl. Acad. Sci. USA. 89:11993-11997.

67. Komers, R., Lindsley, J.N., Oyama, T.T., Allison, K.M., and Anderson, S. 2000. Role of neuronal NOS (NOS1) in the pathogenesis of renal hemodynamic changes in diabetes. Am. J. Physiol. 279:F573-F583.

68. Komers, R., Oyama, T.T., Chapman, J.G., Allison, K.M., and Anderson, S. 2000. Effects of systemic inhibition of neuronal nitric oxide synthase in diabetic rats. Hypertension. 34:655-661.

69. Brater, D.C. 1999. Effects of nonsteroidal anti-inflammatory drugs on renal function: focus on cyclooxygenase-2-selective inhibition. Am. J. Med. 107:65S-71S.

70. Sanchez, P.L., Salgado, L.M., Ferreri, N.R., and Escalante, B. 1999. Effect of cyclooxygenase-2 inhibition on renal function after renal ablation. Hypertension. 34:848-853.

71. Wang, J.-L., Cheng, H.-F., Shappell, S., and Harris, R.C. 2000. A selective cyclooxygenase-2 inhibitor decreases proteinuria and retards progressive renal injury in rats. Kidney Int. 57:2334-2342. 